\title{
Settlement of a pile under cyclic lateral loads in dry sand
}

\author{
GANG ZHENG*, JIBIN SUN*, TIANQI ZHANG† and YU DIAO*
}

\begin{abstract}
It is found through centrifuge model tests that the cyclic lateral load on a pile reduces the shaft friction and induces additional pile settlement. A theoretical model using the load-transfer method was proposed for the settlement prediction of cyclic laterally loaded piles in dry sand. A simple formula was established to quickly predict the pile settlement in practical engineering. The theoretical model provided a reasonable estimate of the pile settlement, while the predictions from the proposed quick prediction formula were relatively conservative. A new concept of 'settlement-controlled design' was proposed to advance the methodology for the design of a pile by considering potential settlement after many cycles of lateral loads. According to the design plane derived from this study, it was suggested that the design-state points should be limited to the convergent zone.
\end{abstract}

KEYWORDS: cyclic lateral load; geotechnical engineering; piles \& piling; pile settlement; quick prediction; settlement; settlement-controlled design; theoretical analysis; theoretical model

\section{INTRODUCTION}

Pile foundations have been widely adopted for the construction of a variety of infrastructures, such as viaducts, high-rise buildings and offshore structures (Zhang et al., 2005; Kong et al., 2019). As the basic components that support superstructures, piles are inevitably subjected to cyclic lateral loads (e.g. the starting and braking forces of vehicles acting on a viaduct, earthquake forces acting on a high-rise building and wind or wave loads acting on an offshore wind turbine) during their service lives.

In recent decades, many innovative studies on laterally loaded piles have been documented in the literature (Broms, 1964; Matlock, 1970; Reese et al., 1974; Baguelin et al., 1977; Banerjee \& Davies, 1978; Meyerhof et al., 1981; Randolph, 1981, 2003, Randolph \& Schneider, 2018; Budhu \& Davies, 1987; Sun \& Pires, 1993; Meyerhof, 1995; Poulos et al., 1995; Rollins et al., 1998; Zhang, 2009; Leblanc et al., 2010; Zhang et al., 2016; Hong et al., 2017). Relatively complete industry standards have also been released for the design of pile foundations (BSI, 1997; MOHURD, 2008; API, 2015). However, attentive engineers may notice that these documents are focused on the deformation and horizontal capacity of the pile, whereas the vertical response of a pile under cyclic lateral loads has barely been mentioned.

Pile response analyses have confirmed that pile-supported buildings exhibit obvious settlement during earthquakes (Tokimatsu \& Asaka, 1998; Stringer \& Madabhushi, 2011). However, it is difficult to obtain a consensus on the reasons for pile settlements. One mainstream opinion was that the seismic failure of soil gives rise to the subsidence of piles, which emphasises the loss of soil strength. The most typical case would be the liquefaction of the soil, which has been proposed as the cause of excessive pile settlement during

$\overline{\text { Manuscript received } 18 \text { May 2021; revised manuscript accepted } 6}$ September 2021.

Discussion on this paper is welcomed by the editor.

Published with permission by the ICE under the CC-BY 4.0 license. (http://creativecommons.org/licenses/by/4.0/)

* School of Civil Engineering, Tianjin University, Tianjin,

P. R. China.

$\uparrow$ School of Civil Engineering, Tianjin University, Tianjin,

P. R. China (Orcid:0000-0003-0145-973X). earthquakes, for example, Niigata in 1964, Hanshin in 1995 and Kobe in 1995 (Hamada \& O'Rourke, 1993; AHG, 1995; EQE, 1995). A survey of the 1985 Mexico earthquake deviated from this point of view (Mendoza \& Auvinet, 1988). Most obviously, buildings with piles driven in clay (typical non-liquefiable soil) also exhibited substantial subsidence. According to Mendoza \& Auvinet (1988), significant settlement mainly occurred at friction piles, whereas point-bearing (or end-bearing) piles performed much better during the earthquake. This finding inspired another hypothesis that the adhesion or friction at the pilesoil interface degraded under seismic loading. The force equilibrium was disrupted to generate additional settlement. However, there has been little research that attempts to validate and clarify this possibility, which means that the truth behind this theory is yet to be revealed.

To reveal the mechanism of the vertical displacements of a pile under cyclic lateral loads, a series of centrifuge model tests was conducted by Zheng et al. (2021). These tests provided evidence for the transmission of the shaft friction lost on the pile tip, which caused additional pile settlement. In this study, a theoretical model using the load-transfer method was proposed to predict the settlement of a pile under cyclic lateral loads in dry sand. A simple formula was established to predict pile settlement quickly in practical engineering. A new concept of 'settlement-controlled design' was proposed to advance the methodology for the design of a pile by considering potential settlement after many cycles of lateral loads.

\section{BRIEF REVIEW OF THE CENTRIFUGE MODEL TESTS}

Zheng et al. (2021) conducted centrifuge model tests at $100 \mathrm{~g}$ to reveal the mechanism of the vertical displacements of a pile under cyclic lateral loads. Cyclic lateral loads were applied to a pile model with a diameter of $6 \mathrm{~mm}$ by way of a self-designed loading system, as shown in Fig. 1. The lateral load was applied by the displacement-controlled method with the amplitude of horizontal displacement denoted as $a$. Standard weights were installed on the top of the pile to simulate the vertical load, $F_{\mathrm{v}}$. More details of the centrifuge modelling process can be found in Zheng et al. (2021).

The results of a typical test with $F_{\mathrm{v}}=60 \mathrm{~N}$ and $a=1.6 \mathrm{~mm}$ are shown in Fig. 2, where $s_{\mathrm{v}}$ and $f_{\mathrm{b}}$ denote the pile settlement and the measured force acting on the pile base, respectively. 

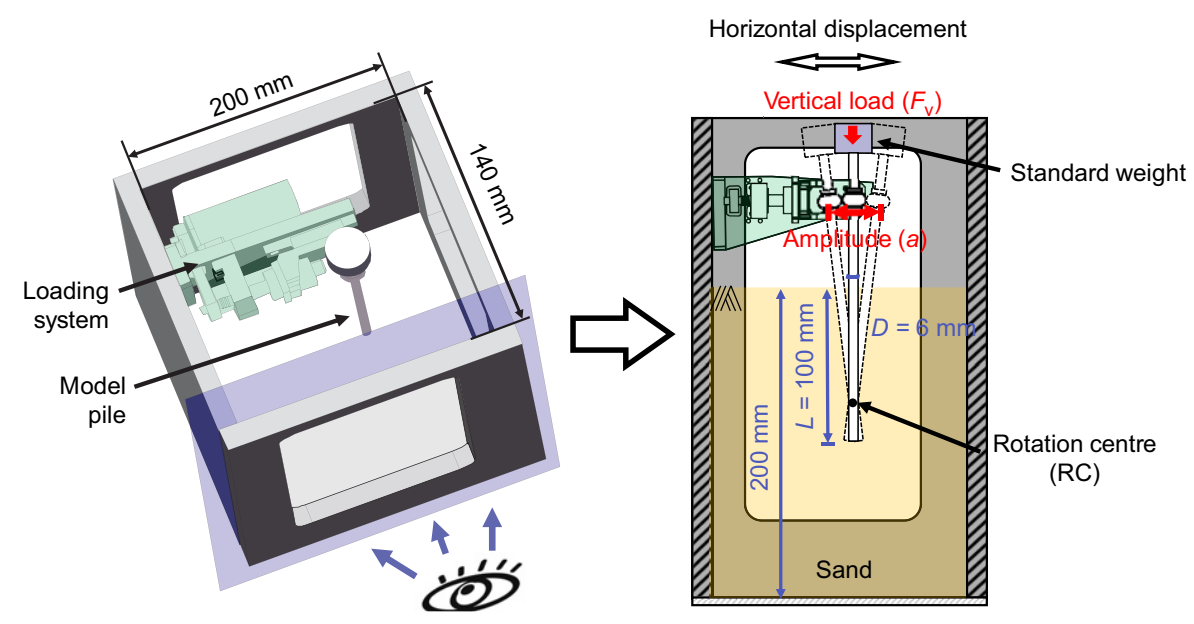

Fig. 1. Schematic diagram of the centrifuge model

The pile settlement increased non-linearly with increasing cycle number and stabilised after a certain number of cycles. The measured force acting on the pile base $f_{\mathrm{b}}$ provided further insight into the settlement process. The curve of the measured force acting on the pile base $f_{\mathrm{b}}$ plotted against the number of cycles $n$ shows a trend that is highly consistent with the $s_{\mathrm{v}}$ plotted against $n$ curve. This implies an intrinsic relationship between the pile-settlement behaviour and the base force. Since no vertical loads were applied to the pile during cyclic loading, it is reasonable to conclude that the mobilised shaft friction of the pile was transmitted to the pile base, which caused an increase in both $f_{\mathrm{b}}$ and $s_{\mathrm{v}}$ (Zheng et al., 2021).

\section{THEORETICAL MODEL}

\section{Load-transfer model}

Under the framework of the classic load-transfer method, a theoretical model was proposed to calculate the pile settlement under cyclic lateral loading. The soil continuum around the pile shaft was discretised into a series of infinitesimal areas. Each area of soil had its own loadtransfer curves in three directions - namely, the radial and tangential directions in the cross-section and the tangential direction in the longitudinal section. These curves defined the relationship between the stress (cf. normal pressure $\sigma_{\mathrm{n}}$, horizontal shear stress $\tau_{\mathrm{h}}$ and vertical shear stress $\tau_{\mathrm{v}}$ in Fig. 3) applied at the pile shaft and the local displacement of

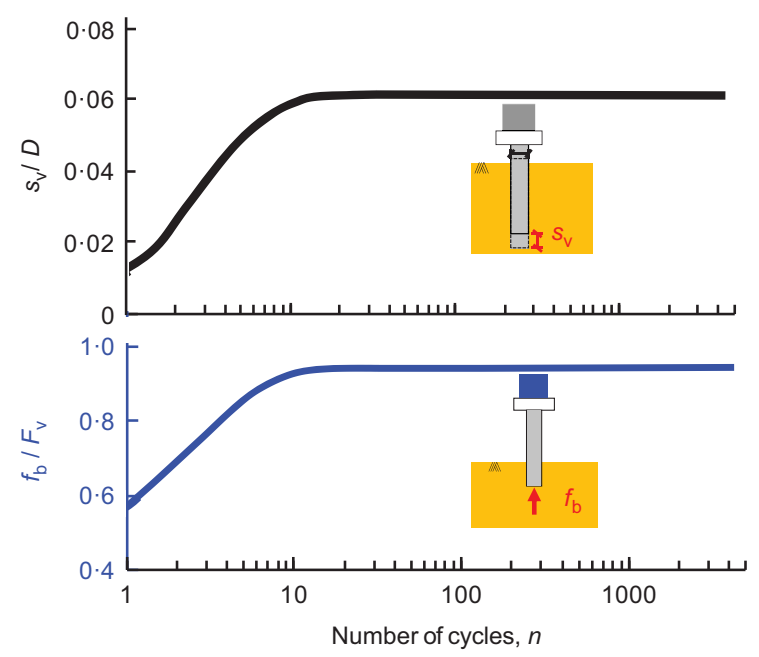

Fig. 2. Experimental results of a typical test the soil relative to the pile (radial and tangential displacement). Similarly, the soil underneath the pile base was characterised by one load-transfer curve in the vertical direction (cf. $\sigma_{\mathrm{b}}$ in Fig. 3). According to Li et al. (2012), the load-transfer curves adopted the form of a parabola. More details on the load-transfer curves are given in Appendix 1. (For ease of description, half a pile shaft contacting the compacted soil was defined as the front side, while the other half was defined as the back side, as shown in Fig. 3. In Fig. 3, $D_{\mathrm{R}}$ is the depth of the rotation centre, RC, at which no horizontal displacement is anticipated. It should be noted that the front side and back side are not constant because the lateral moving direction of the pile under cyclic loads may reverse.)

When the pile head moves horizontally at a distance of $\mathrm{d} a$, the normal pressure $\sigma_{\mathrm{n}}$ changes to $\sigma_{\mathrm{n} \_\mathrm{d} a}$. On the back side of the pile, the limit shaft friction would decrease due to the decreased normal pressure. If the limit shaft friction was smaller than the mobilised shaft friction, the mobilised shaft friction thereupon would decrease and be equal to the value of the limit shaft friction. In this way, in the $\mathrm{d} a$ movement, the loss in the mobilised shaft friction, $\mathrm{d} F_{\mathrm{f} \_\mathrm{d} a}$, can be calculated as

$$
\mathrm{d} F_{\mathrm{f}_{\_} \mathrm{d} a}=\int_{S} \alpha\left(\tau_{\mathrm{v}}-\tan \delta \times \sigma_{\mathrm{n}_{\_} \mathrm{d} a}\right) \mathrm{d} S
$$

where $\delta$ is the friction angle of the pile-soil interface; $S$ is the surface of the pile shaft; $\tau_{\mathrm{v}}$ is the vertical shear stress (i.e. mobilised shaft friction) before $\mathrm{d} a$ movement; and $\alpha$ is a sign function expressed by

$$
\alpha=\left\{\begin{array}{l}
1, \tau_{\mathrm{v}}>\tan \delta \times \sigma_{\mathrm{n} \_\mathrm{d} a} \\
0, \tau_{\mathrm{v}} \leq \tan \delta \times \sigma_{\mathrm{n} \_\mathrm{d} a}
\end{array}\right.
$$

The loss in the mobilised shaft friction does not disappear but is transmitted to the pile base and pile shaft with a redundant bearing capacity that can carry the vertical loads. The forces that were transmitted to the pile base, $\mathrm{d} F_{\mathrm{f}_{-} \mathrm{d} a, \mathrm{~b}}$, can be calculated by

$$
\mathrm{d} F_{\mathrm{f}_{-} \mathrm{d} a, \mathrm{~b}}=\mathrm{d} F_{\mathrm{f}_{-} \mathrm{d} a} \frac{K_{\mathrm{b} \__{-} \mathrm{d} a}}{K_{\mathrm{b} \_\mathrm{d} a}+K_{\mathrm{S} \_\mathrm{d} a}}
$$

where $K_{\mathrm{b} \_\mathrm{d} a}$ and $K_{\mathrm{s} \_\mathrm{d} a}$ represent the contribution of the pile base and shaft, respectively, to the stiffness of the pile against vertical displacement.

In this $\mathrm{d} a$-movement, the settlement of the pile, $\mathrm{d} s_{\mathrm{v}}$, can be obtained by

$$
\mathrm{d} s_{\mathrm{v}}=\frac{\mathrm{d} F_{\mathrm{f}_{-} \mathrm{d} a, \mathrm{~b}}}{K_{\mathrm{b}_{-} \mathrm{d} a}}
$$




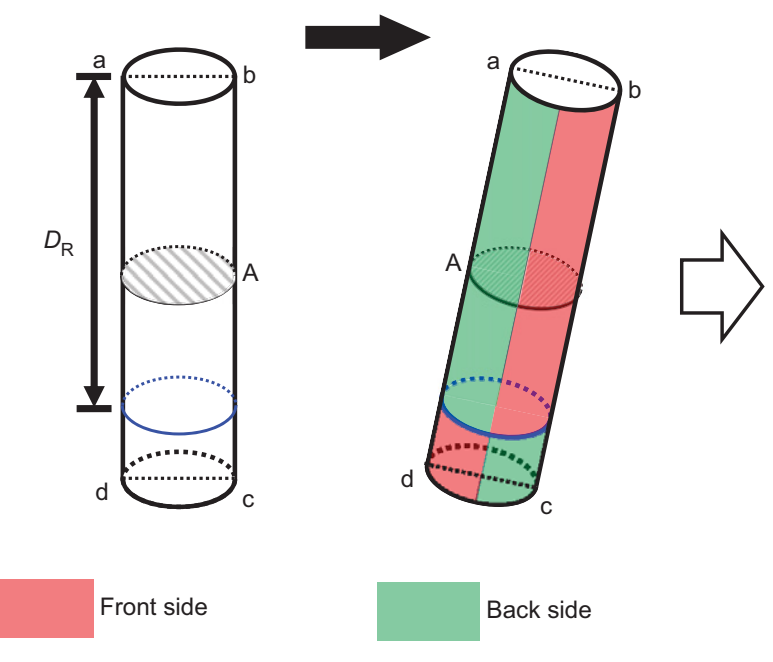

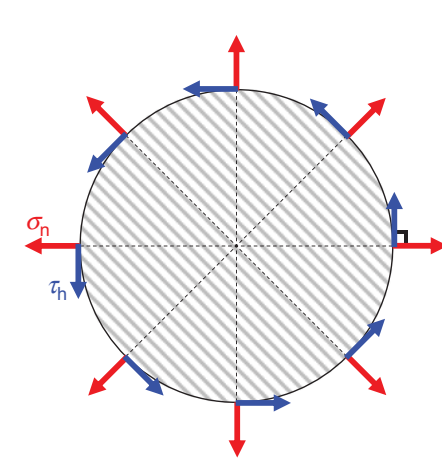

Cross-section A

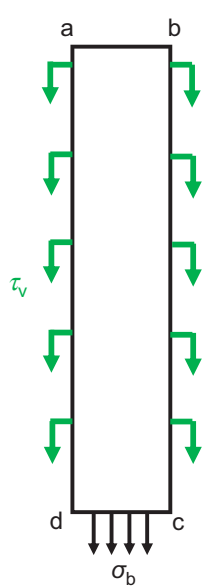

Longitudinal section abcd

Fig. 3. Schematic diagram of the load-transfer model

The settlement of the pile after many cycles of lateral loads, $s_{\mathrm{v}}$, can be expressed by

$$
s_{\mathrm{V}}=\sum_{0}^{i}\left(\int_{0}^{a_{i}} \mathrm{~d} s_{\mathrm{V}}\right)
$$

where $i$ is the number of half-cycle movements and $a_{i}$ is the horizontal displacement of the pile at the $i$ th half-cycle movement. (In this study, when the pile moved from the left-most position to the right-most position (or vice versa), the pile was considered to have completed one 'half-cycle movement'.)

\section{Validation}

To verify the accuracy of the proposed theoretical model, it is used to predict the data collected from centrifuge model tests conducted by Zheng et al. (2021). The settlement plotted against cycle number curves from the centrifuge model test (denoted CT in the figure) and theoretical model (denoted TM in the figure) are shown in Fig. 4. Good agreements have been achieved. The comparison for the cases in which the amplitude of the horizontal displacement, $a$, was $1.6 \mathrm{~mm}$, while the vertical loads, $F_{\mathrm{v}}$, were $40 \mathrm{~N}, 60 \mathrm{~N}$ and $80 \mathrm{~N}$ is shown in Fig. 4(a). The test data and calculated results show that the pile settlement was greater when $F_{\mathrm{v}}$ was larger. The cases for an $F_{\mathrm{v}}$ of $60 \mathrm{~N}$ and the values of $a$ of $0.2 \mathrm{~mm}, 0.4 \mathrm{~mm}, 0.8 \mathrm{~mm}, 1.6 \mathrm{~mm}$ and $2.4 \mathrm{~mm}$ are shown in Fig. 4(b). Similarly, both the test data and calculated results indicated that the pile settlement could be greater when the amplitude of horizontal displacement, $a$, was larger.

Predictions of the mobilised shaft friction in the vertical slice abcd (see Fig. 5(a)) after the first cycle for the case of $a=1.6 \mathrm{~mm}$ and $F_{\mathrm{v}}=60 \mathrm{~N}$ are shown in Fig. 5(a). The mobilised shaft friction on the front side exhibited steady growth, while the mobilised shaft friction on the back side gradually vanished during the movement of the pile. The mobilised shaft friction on the back side in the far end (the part away from the RC) could quickly decrease to zero. However, a delay in the reduction in the mobilised shaft friction was observed near the RC (as shown in Fig. 5(a)). The mobilised shaft friction near the $\mathrm{RC}$ remained almost unchanged when the horizontal displacement was less than $a / 4$.

After many cycles of lateral loads, most of the mobilised shaft friction on both the back and front sides is lost except in a region near the $\mathrm{RC}$, in which the mobilised shaft friction is finally maintained at a certain level (cf. Fig. 5(b)). In the present study, this region is called the friction core.

It should be noted that the response of the soil around a pile under cyclic lateral loads in dry sand can be very complicated. For instance, both soil densification and strain ratcheting were found in similar studies $(\mathrm{Ng}$ et al., 1998a, 1998b). However, for ease of analysis, these effects were not considered in the theoretical model presented in this study.

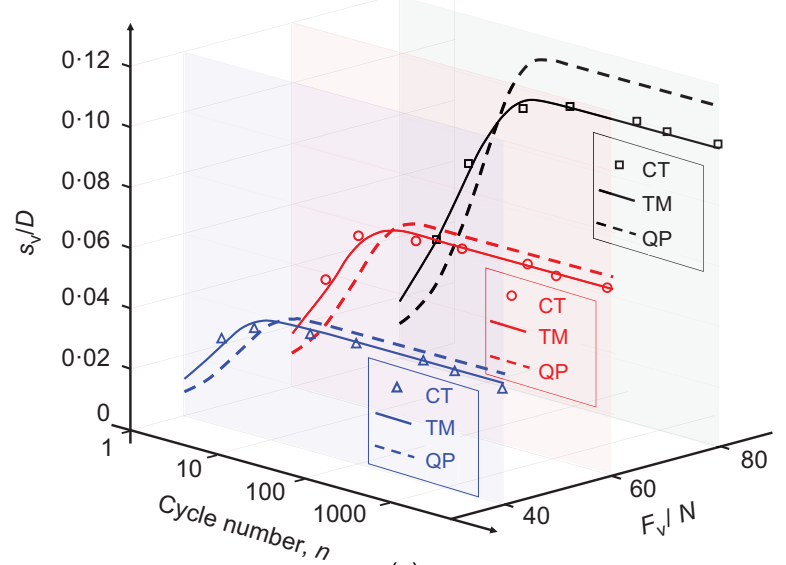

(a)

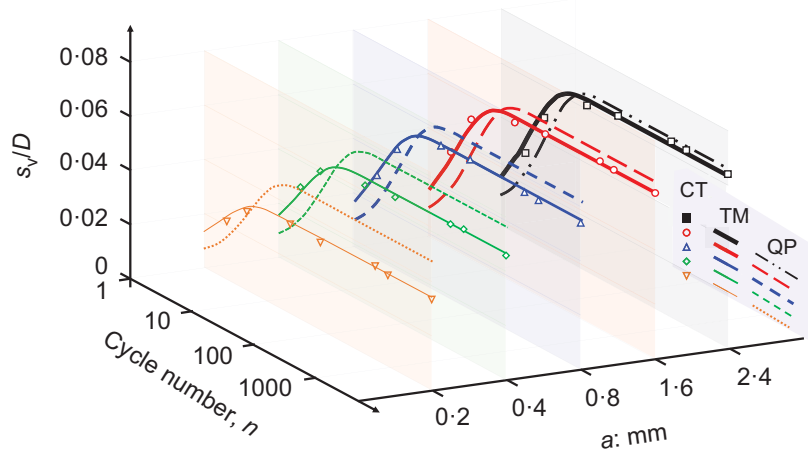

(b)

Fig. 4. Comparison of the test data and the calculation results: (a) tests with different $F_{\mathrm{v}}$ values; (b) tests with different $a$ values 


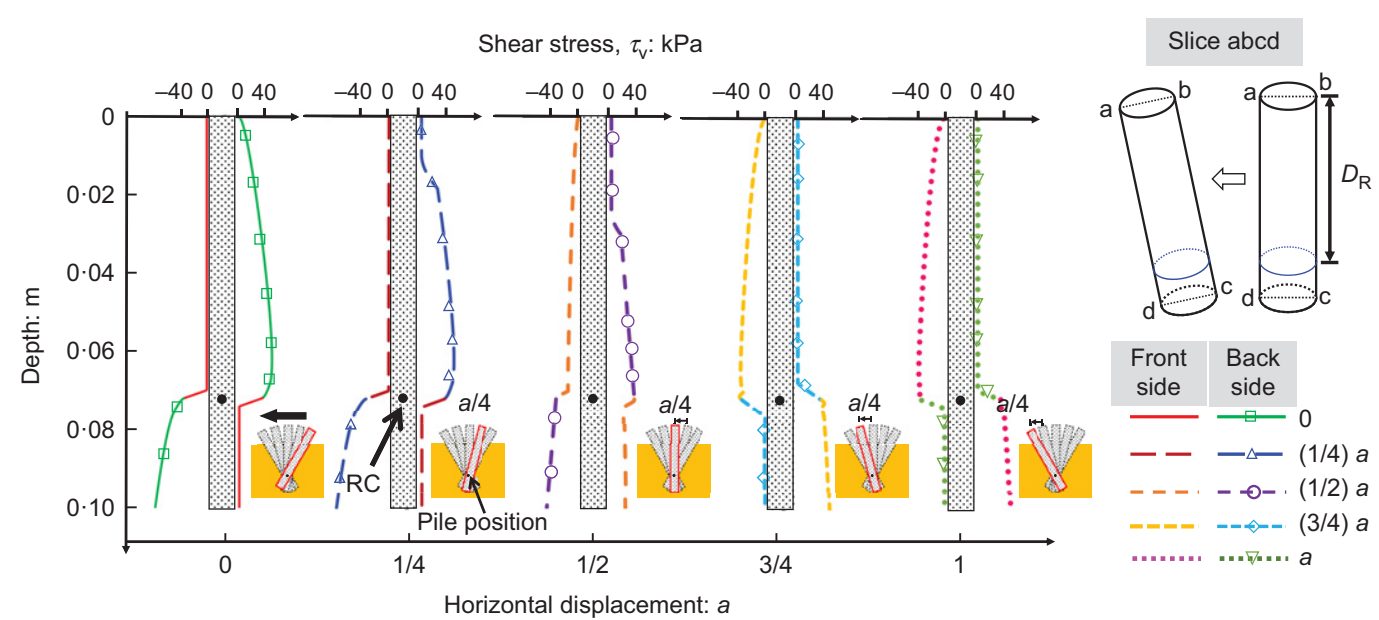

(a)

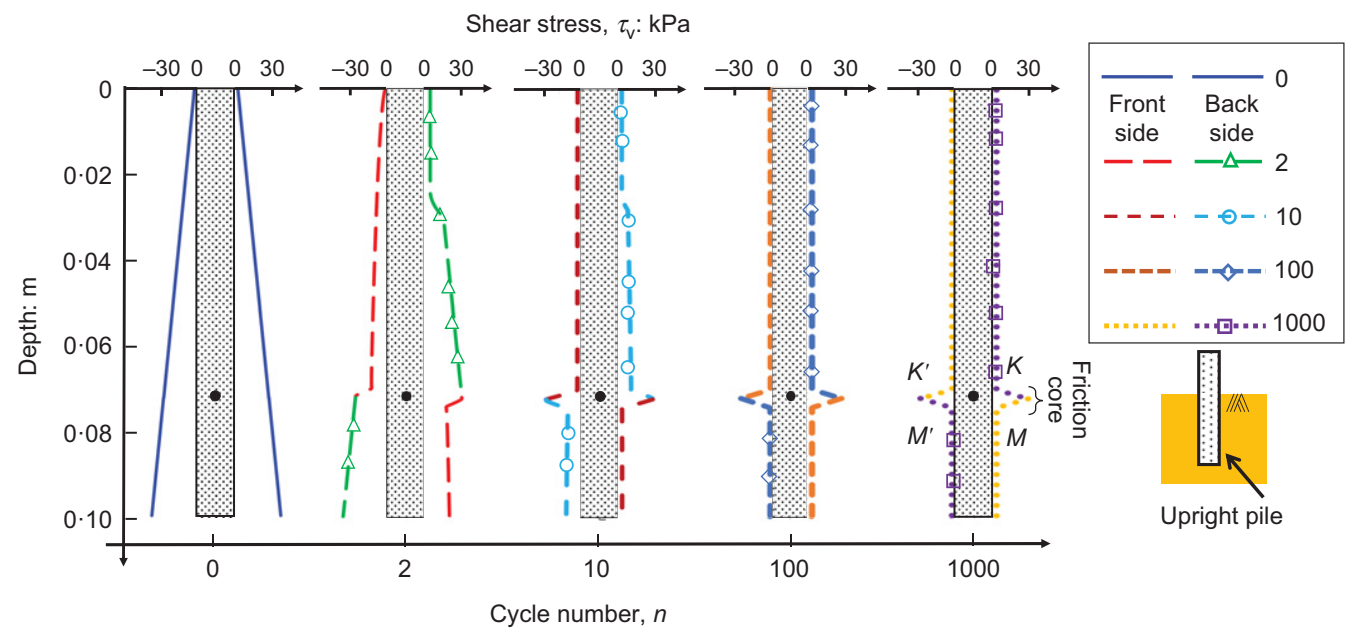

(b)

Fig. 5. Variations in the mobilised shaft friction during cyclic lateral loading (all dimensions in model scale): (a) pile at different positions in the first cycle; (b) upright pile under different cycles

\section{A quick prediction formula}

Although the theoretical model provided satisfactory predictions for pile settlement under cyclic lateral loads, it is still too complicated for engineers to use in engineering practice. A simple formula was proposed to achieve a quick prediction of the pile settlement induced by cyclic lateral loads. The following simplifications are made to derive the quick prediction $(\mathrm{QP})$ formula.

(a) The load-transfer curves adopt a linear form. The slopes of the load-transfer curves, $k_{\mathrm{n}_{-} \mathrm{QP}}, k_{\mathrm{h}_{-} \mathrm{QP}}$ and $k_{\mathrm{v}_{-} \mathrm{QP}}$, corresponding to $\sigma_{\mathrm{n}}, \tau_{\mathrm{h}}$ and $\tau_{\mathrm{v}}$, respectively, can be calculated by (Li et al., 2012)

$$
\begin{aligned}
& k_{\mathrm{n}_{-} \mathrm{QP}}=\frac{8}{\pi(1-v) D} G_{\mathrm{s}, \mathrm{ini}} \\
& k_{\mathrm{h}_{-} \mathrm{QP}}=\frac{G_{\mathrm{s}, \mathrm{ini}}}{\varsigma} \\
& k_{\mathrm{v}_{-} \mathrm{QP}}=\frac{G_{\mathrm{s}, \mathrm{ini}}}{\varsigma}
\end{aligned}
$$

where $v$ is the Poisson's ratio of the sand; $G_{\mathrm{s} \text {,ini }}$ is the initial shear modulus of the soil; and $\zeta$ is a dimensionless coefficient. The determinations of these variables are consistent with those in the theoretical model, which can be found in Appendix 1.
The slopes of the load-transfer curves, $k_{\mathrm{b}_{-} \mathrm{QP}}$, corresponding to $\sigma_{\mathrm{b}}$, can be calculated by

$$
k_{\mathrm{b}_{-} \mathrm{QP}}=\frac{8}{\pi(1-v) D} G_{\mathrm{s}, \text { ini }} \beta
$$

where $\beta$ is a coefficient that can be calculated by

$$
\beta=\frac{1}{2}\left(\sqrt{\frac{\sigma_{\mathrm{b}, \max }-\sigma_{\mathrm{b} 0}}{\sigma_{\mathrm{b}, \max }}}+\sqrt{\frac{\sigma_{\mathrm{b}, \max }-\sigma_{\mathrm{b} 0}-\Delta F_{\mathrm{M}_{-} \mathrm{QP}}}{\sigma_{\mathrm{b}, \max }}}\right)
$$

where $\sigma_{\mathrm{b} \text { max }}$ is the maximum base pressure of the pile; $\sigma_{\mathrm{b} 0}$ is the initial stress acting on the pile base; and $\Delta F_{\mathrm{M}_{-} \mathrm{QP}}$ is the loss of the shaft friction of the pile during the lateral loading process. More details for the calculation of $\Delta F_{\mathrm{M} \_\mathrm{QP}}$ can be seen in simplification $(f)$ below.

As the distribution of the normal pressures acting on the pile in each cycle are the same, the depths of points $K\left(K^{\prime}\right)$ and $M\left(M^{\prime}\right)$ (see Fig. 5(b)) are

$$
\begin{aligned}
& D_{\mathrm{K}}=\frac{2 A D_{\mathrm{RC}}+K_{0}^{2} \gamma^{2}-\sqrt{K_{0}^{4} \gamma^{4}+4 A D_{\mathrm{RC}} K_{0}^{2} \gamma^{2}}}{2 A} \\
& D_{\mathrm{M}}=\frac{2 A D_{\mathrm{RC}}+K_{0}^{2} \gamma^{2}+\sqrt{K_{0}^{4} \gamma^{4}+4 A D_{\mathrm{RC}} K_{0}^{2} \gamma^{2}}}{2 A}
\end{aligned}
$$




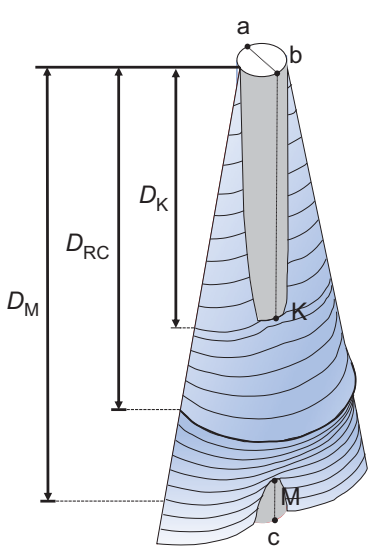

(a)

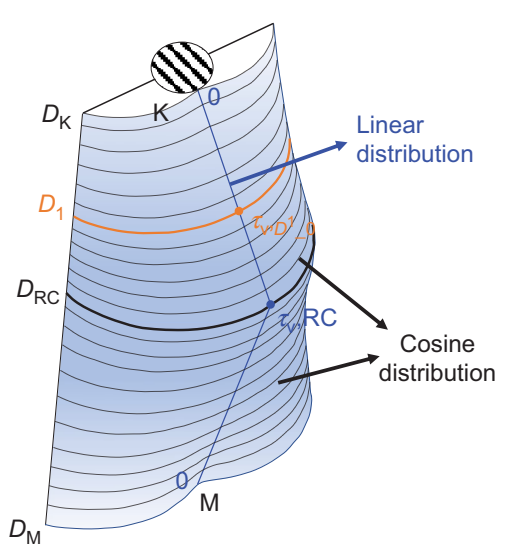

(b)

Fig. 6. Simplification of the friction core: (a) friction core according to the theoretical model; (b) friction core after simplification

$$
A=\frac{4 m^{2} \sigma_{\mathrm{r}} \gamma a^{2}\left(1+2 K_{0}\right)}{3 \pi^{2} D^{2}\left(1-v^{2}\right)^{2}\left(D_{\mathrm{RC}}+e_{\mathrm{L}}\right)^{2}}
$$

where $D_{\mathrm{RC}}$ is the depth of the $\mathrm{RC}$; and $e_{\mathrm{L}}$ is the eccentricity of the lateral load.

The linear load-transfer curves also result in a constant stiffness ratio, $K_{\mathrm{b}_{-} \mathrm{QP}} / K_{\mathrm{s}_{-} \mathrm{QP}}$, where $K_{\mathrm{b}_{-} \mathrm{QP}}$ and $K_{\text {s_QP }}$ are the stiffness contributions of the pile base and pile shaft against the vertical displacements, respectively. The lost shaft friction is transmitted to the pile base at a constant ratio, $r$, which can be calculated by

$$
\eta_{\mathrm{QP}}=\frac{K_{\mathrm{b}_{-} \mathrm{QP}}}{K_{\mathrm{b}_{-} \mathrm{QP}}+K_{\mathrm{s}_{-} \mathrm{QP}}}
$$

where $K_{\mathrm{b} \_ \text {QP }}$ can be calculated by

$$
K_{\mathrm{b} \_\mathrm{QP}}=\pi r^{2} k_{\mathrm{b} \_\mathrm{QP}}
$$

where $r$ is the radius of the pile.

(b) The stiffness of the pile shaft resisting the vertical displacement considers the contribution of only the front side. $K_{\mathrm{s}_{-} \mathrm{QP}}$ can be calculated by

$$
K_{\mathrm{s}_{-} \mathrm{QP}}=\frac{\pi r m \sigma_{\mathrm{r}}^{0.5} L^{3 / 2} \sqrt{\left(1+2 K_{0}\right) \gamma}}{12 \sqrt{3}(1+v)}
$$

(c) The shaft friction of the pile in the friction core was assumed to be fully mobilised, which means that the mobilised shaft friction in the friction core is equal to the limit shaft friction and proportional to the normal pressure. (d) The morphology of the friction core with an accurate profile from the theoretical model, as shown in Fig. 6(a), is simplified to that shown in Fig. 6(b).

(e) The distribution of the normal pressures acting on slice abcd of the pile in the friction core is assumed to be linear, as shown in Fig. 6(b). The vertical shear stress acting on slice abcd at depth $D_{1}, \tau_{\mathrm{v}, D_{1} \_0}$, can be calculated by

$$
\tau_{\mathrm{V}, D_{1} \_0}=\left(\frac{D_{1}-D_{\mathrm{K}}}{D_{\mathrm{RC}}-D_{\mathrm{K}}}\right) \tau_{\mathrm{v}, D_{\mathrm{RC}}}
$$

where $\tau_{\mathrm{v}, D_{\mathrm{RC}}}$ is the shaft friction at depth $D_{\mathrm{RC}}$ and can be calculated by

$$
\tau_{\mathrm{v}, D_{\mathrm{RC}}}=\tan \delta \times K_{0} \gamma D_{\mathrm{RC}}
$$

( $f$ ) The distribution of the normal pressures acting on the pile shafts at the same depth was assumed to be cosinusoidal, as shown in Fig. 6(b). The vertical shear stress acting on the pile at depth $D_{1}$ is defined as $\tau_{\mathrm{v}, D_{1} \_} \theta$, which can be calculated by

$$
\tau_{\mathrm{v}, D_{1 \_} \theta}=\tau_{\mathrm{v}, D_{1} \_ \text {ini }}-\left(\tau_{\mathrm{v}, D_{1} \text { ini }}-\tau_{\mathrm{v}, D_{1 \_} 0}\right)|\cos \theta|
$$

where $\tau_{\mathrm{v}, D_{1} \text { ini }}$ can be calculated by

$$
\tau_{\mathrm{v}, D_{1} \_ \text {ini }}=\tan \delta \times K_{0} \gamma D_{1}
$$

The settlement of a pile under cyclic lateral loads for quick prediction after $j$ half-cycle movements, $S_{j_{-} \mathrm{QP}}$, can be expressed as

$$
\begin{aligned}
& \frac{\Delta F_{\mathrm{M}_{-} \mathrm{QP}} \eta_{\mathrm{QP}}}{2 K_{\mathrm{b} \_\mathrm{QP}}}, \quad j=1 \\
& S_{j_{-} \mathrm{QP}}=\frac{\Delta F_{\mathrm{M}_{-} \mathrm{QP}}\left\{\eta_{\mathrm{QP}}+\left(2-\eta_{\mathrm{QP}}\right)\left[1-\left(1-\eta_{\mathrm{QP}}\right)^{j-1}\right]\right\}}{2 K_{\mathrm{b}_{-} \mathrm{QP}}}, j \geq 2
\end{aligned}
$$

where $\Delta F_{\mathrm{M}_{-} \mathrm{QP}}$ can be calculated by

$$
\begin{aligned}
& \Delta F_{\mathrm{M}_{-} \mathrm{QP}}=F_{\mathrm{M} 0} \\
& \quad-r \tan \delta K_{0} \gamma\left\{\begin{array}{l}
\left(D_{\mathrm{RC}}-D_{\mathrm{K}}\right)\left[\pi D_{\mathrm{RC}}+(\pi-2) D_{\mathrm{K}}\right]+ \\
{\left[\min \left(L, D_{\mathrm{M}}\right)-D_{\mathrm{RC}}\right]\left[\pi D_{\mathrm{RC}}+(\pi-2) \min \left(L, D_{\mathrm{M}}\right)\right]}
\end{array}\right\}
\end{aligned}
$$

where $F_{\mathrm{M} 0}$ is the mobilised shaft friction of the pile before cyclic lateral loading.

The results from the quick prediction are also presented in Fig. 4. It can be found that the results of the quick prediction were slightly larger than those from the centrifuge model test and the theoretical model. The predictions from the proposed quick prediction formula are relatively conservative.

\section{SETTLEMENT-CONTROLLED DESIGN}

As discussed in earlier section 'Validation', the transmitted shaft friction to the pile base may exceed the redundancy of the vertical bearing capacity of the pile base if $F_{\mathrm{v}}$ or $a$ is very large. The settlement of the pile may become divergent with respect to the increase in cycle number. Two sets of calculations were performed to show this possibility. Three cases were considered with an initial tip resistance, $f_{\mathrm{b} 0}$, of $60 \mathrm{~N}$; an initial mobilised shaft friction to the initial tip resistance ratio, $\left(F_{\mathrm{v}}-f_{\mathrm{b} 0}\right) / f_{\mathrm{b} 0}$, of 0.43 ; and values of $a$ of $0.6 \mathrm{~mm}, 0.7 \mathrm{~mm}$ and $0.8 \mathrm{~mm}$. The divergent settlements plotted against cycle number curves are shown in Fig. 7(a). When $a$ was $0.6 \mathrm{~mm}$, the settlement of the pile was convergent. When $a$ was $0.8 \mathrm{~mm}$, the settlement of the pile was divergent. When $a$ was $0.7 \mathrm{~mm}$, the pile was in a limit 


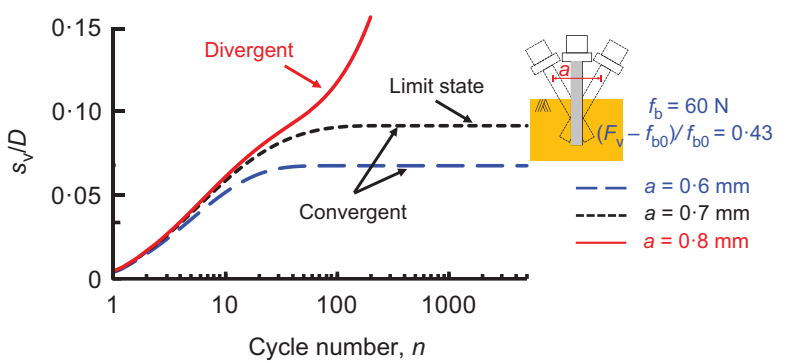

(a)

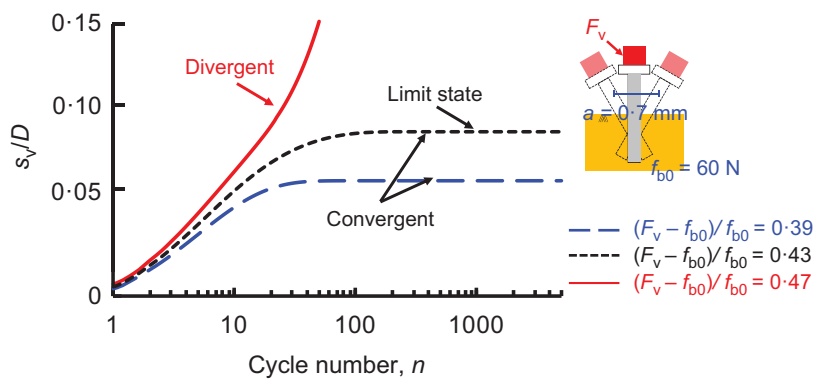

(b)

Fig. 7. Divergent settlement due to increasing $F_{\mathrm{v}}$ or $a$ : (a) increasing $a$; (b) increasing $F_{\mathrm{v}}$

state, in which a very small increment in $a$ would induce divergent pile settlement. The settlements against cycle number curves with $a$ of $0.7 \mathrm{~mm}, f_{\mathrm{b} 0}$ of $60 \mathrm{~N}$ and $\left(F_{\mathrm{v}}-f_{\mathrm{b} 0}\right) / f_{\mathrm{b} 0}$ of $0.39,0.43$ and 0.47 are shown in Fig. $7(\mathrm{~b})$. When $\left(F_{\mathrm{v}}-f_{\mathrm{b} 0}\right) / f_{\mathrm{b} 0}$ was $0 \cdot 39$, the settlement of the pile was convergent. When $\left(F_{\mathrm{v}}-f_{\mathrm{b} 0}\right) / f_{\mathrm{b} 0}$ was $0 \cdot 47$, the settlement of the pile was divergent. Similarly, when $\left(F_{\mathrm{v}}-f_{\mathrm{b} 0}\right) / f_{\mathrm{b} 0}$ was $0 \cdot 43$, the pile was in a limit state, in which a very small increment in $F_{\mathrm{v}}$ would induce divergent pile settlement.

Inspired by the above-mentioned problem, a new concept, 'settlement-controlled design', for a pile under cyclic lateral loads, was put forward (see Appendix 2). A threedimensional coordinate system is first established as shown in Fig. 8. The three coordinates are set as $a / D,\left(F_{\mathrm{v}}-f_{\mathrm{b} 0}\right) / f_{\mathrm{b} 0}$ and $s_{\mathrm{v}} / D$ where $\left(F_{\mathrm{v}}-f_{\mathrm{b} 0}\right) / f_{\mathrm{b} 0}, a / D$ and $s_{\mathrm{v}} / D$ represent the apportionment of the vertical loads on the pile, the magnitude of the horizontal displacements and the settlement of a pile after many cycles of lateral loads, respectively. In Fig. $8, l_{0.017}, l_{0.033}, l_{0.050}$ and $l_{0.067}$ are the contour lines when $s_{\mathrm{v}} / D$ is $0.017,0.033,0.050$ and 0.067 , respectively. The contour lines were obtained from the theoretical model with an $f_{\mathrm{b} 0}$ of $60 \mathrm{~N}$, and the other parameters were the same

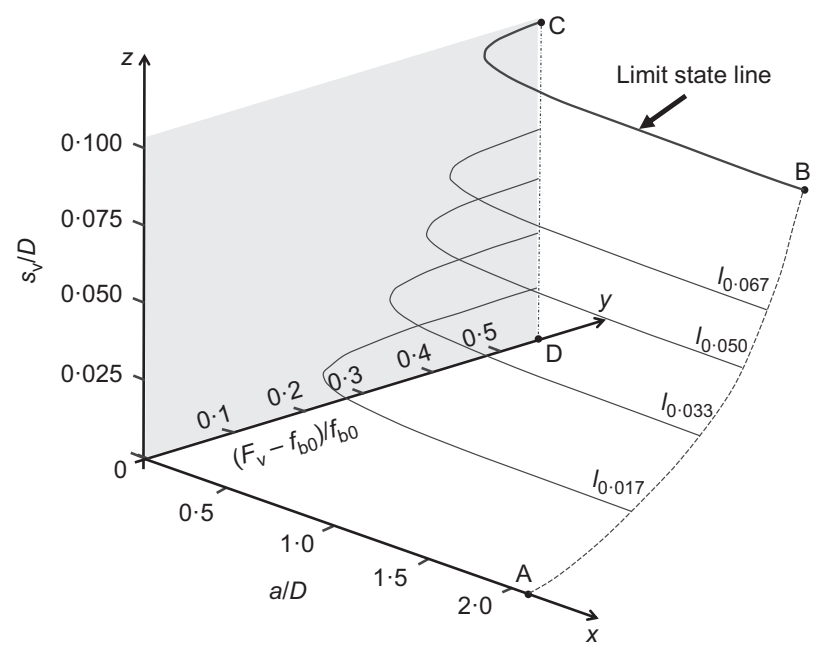

Fig. 8. Contour lines of $s_{\mathrm{v}} / D$ as those in the centrifuge model tests. All settlement contour lines are on surface OABCD. Line $\mathrm{CB}$ on surface OABCD is the contour line of the maximum $s_{\mathrm{v}} / D$. Therefore, on line CB, the pile is in a limit state, and any increments in $a$ or $F_{\mathrm{v}}$ can lead to divergent settlement.

A design plane could be obtained by projecting the surface in Fig. 8 on plane $x \mathrm{O} y$, as shown in Fig. 9. On the design plane, point $\mathrm{O}$ on the $\left(F_{\mathrm{v}}-f_{\mathrm{b} 0}\right) / f_{\mathrm{b} 0}$-axis indicates that the mobilised shaft friction is zero, and point $F$ represents that the limit shaft friction of the pile is mobilised. Therefore, any point $\left(a / D,\left(F_{\mathrm{v}}-f_{\mathrm{b} 0}\right) / f_{\mathrm{b} 0}\right)$ can be taken as a design-state point of the pile.

The design plane was divided into three zones by two lines, EI and GH. Line EI is a straight line that is parallel to the $a / D$-axis. The value of point $\mathrm{E}$ on the $\left(F_{\mathrm{v}}-f_{\mathrm{b} 0}\right) / f_{\mathrm{b} 0}$-axis can be calculated by

$$
E_{\left(F_{\mathrm{v}}-f_{\mathrm{b} 0}\right) / f_{\mathrm{b} 0}}=\frac{f_{\mathrm{b}, \max }-f_{\mathrm{b} 0}}{f_{\mathrm{b} 0}}
$$

where $f_{\mathrm{b}, \max }$ is the maximum tip resistance.

Equation (23) demonstrates that point $\mathrm{E}$ represents the situation where the initial mobilised shaft friction of the pile is equal to the redundant bearing capacity of the pile base. Line GH is composed of a series of points, on which the pile would be in the limit state after many cyclic lateral loads.

When the design-state point of the pile was in the zone below line EI, the settlement of the pile would converge; when the design-state point of the pile was in the zone above line $\mathrm{GH}$, the settlement of the pile would diverge; therefore, the two zones were called the convergent zone and divergent zone, respectively. If the design-state point of the pile was in the zone between lines EI and GH, the settlement of the pile was conditionally convergent and dependent on both $\left(F_{\mathrm{v}}-f_{\mathrm{b} 0}\right) / f_{\mathrm{b} 0}$ and $a / D$. Therefore, this zone was termed the conditionally convergent zone.

It should be noted that current industry standards do not consider the coupling effect of cyclic lateral loads on the vertical performance of piles. The limit state line for the design-state point was FJ (in other words, the design state was acceptable as long as $\left(F_{\mathrm{v}}-f_{\mathrm{b} 0}\right) / f_{\mathrm{b} 0}$ was smaller than the value of $\mathrm{F}$ on the $\left(F_{\mathrm{v}}-f_{\mathrm{b} 0}\right) / f_{\mathrm{b} 0}$-axis). Under this circumstance, if the design-state point is located above line EI, divergent pile settlement might be produced under cyclic lateral loads according to the calculations presented in this study. This could affect both the service performance and the safety of the superstructures, which ought to be considered in the design stage.

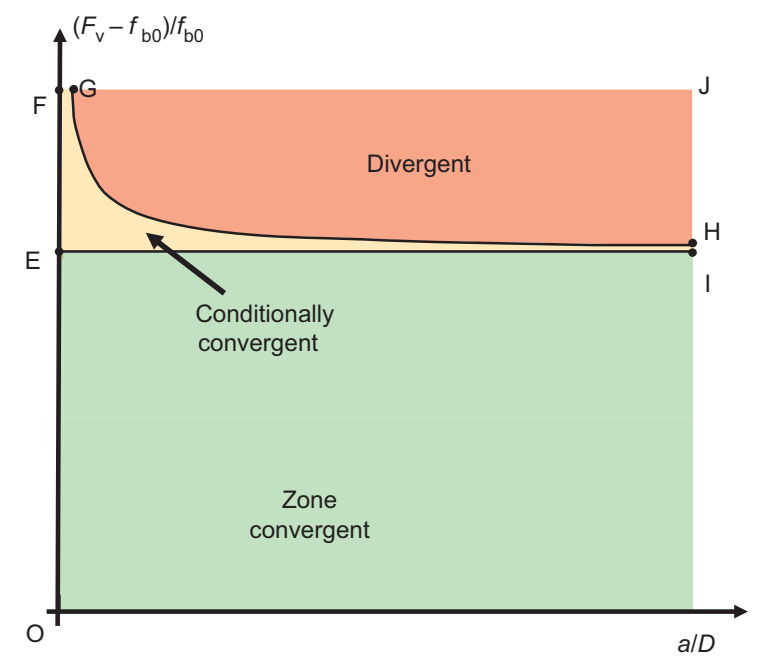

Fig. 9. Design plane for a pile under cyclic lateral loads 
It should be noted that the theoretical framework presented in this study was established for piles driven in dry sand. For a pile driven in wet sand or clay, the settlement behaviour of the pile can be more complex. For instance, if the pile is driven in wet sand, soil liquefaction should be considered, whereas if the pile is driven in clay, pile-ground gaps can be generated under cyclic lateral loads (Zhang et al., 2011; Liu et al., 2018) and should be considered when predicting the settlement of a cyclic laterally loaded pile. In truth, substantial work is still necessary to incorporate these characteristics into the theoretical model.

\section{CONCLUSIONS}

In this study, a theoretical model using the load-transfer method was proposed for the settlement prediction of cyclic laterally loaded piles in dry sand. A simple formula was also established to predict pile settlement quickly in practical engineering. A new concept of 'settlement-controlled design' was proposed to advance the methodology for the design of a pile by considering potential settlement after many cycles of lateral loads. Based on these studies, the following conclusions can be drawn.

(a) The settlement of a pile under cyclic lateral loads can be attributed to the transmission of the lost mobilised shaft friction to the pile base.

(b) Theoretical results can provide a reasonable estimate of the pile settlement under cyclic lateral loads. A friction core is revealed in which the mobilised shaft friction is finally maintained at a certain level under cyclic lateral loads. Both the shape and the size of the friction core are closely related to the magnitude of the horizontal displacement.

(c) The quick prediction formula is a simple and explicit expression with slightly conservative results.

(d) With regard to the division of the design plane, it was suggested that the design-state points should be limited to the convergent zone to eliminate the risk of non-convergent prediction of pile settlement.

\section{DATA AVAILABILITY STATEMENT}

Some or all data used in this study are available from the corresponding author upon reasonable request.

\section{ACKNOWLEDGEMENT}

The authors would like to acknowledge the financial support from the National Natural Science Foundation of China (grant no. 41630641).

\section{APPENDIX 1. DETAILS OF THE THEORETICAL MODEL \\ Load-transfer curve for $\sigma_{n}$}

(a) On the front side, the relationship curve between the normal pressure, $\sigma_{\mathrm{n}_{\mathrm{f}} \mathrm{f}}$, and the normal displacement of the soil, $\omega_{\mathrm{n}_{\_} \mathrm{f}}$, as shown in Fig. 10(a), can be expressed by

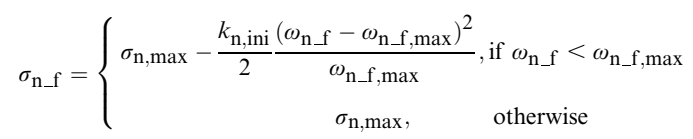

where $k_{\text {n,ini }}$ is the initial gradient of the curves and can be expressed by (Li et al., 2012)

$$
k_{\mathrm{n}, \text { ini }}=\frac{8}{\pi(1-v) D_{\mathrm{p}}} G_{\mathrm{s}, \text { ini }}
$$

where $D_{\mathrm{p}}$ is the diameter of the pile (which was $0.006 \mathrm{~m}$ in the present study); $v$ is Poisson's ratio of the soil (which was $0 \cdot 2$ ); and $G_{\mathrm{s}, \text { ini }}$ is the initial shear modulus of the soil and was calculated according to Li et al. (2012)

$$
G_{\mathrm{s}, \text { ini }}=\chi G_{0}
$$

where $G_{0}$ is the shear modulus of the soil; and $\chi$ is a coefficient that reflects the effect of the pile installation procedure on the shear modulus of the soil. In this study, the model pile was installed in a wished-in-place manner, so the effect of the pile installation procedure on the soil properties was neglected, and $\chi$ was 1 . The shear modulus of the soil, $G_{0}$, was obtained according to the Young's modulus, $E_{\mathrm{s}}$, of the soil, and their relationship was

$$
G_{0}=\frac{E_{\mathrm{s}}}{2(1+v)}
$$

Young's modulus, $E_{\mathrm{s}}$, of the sand could be determined by the equation presented by Janbu (1998)

$$
E_{\mathrm{s}}=m \sigma_{\mathrm{r}}\left(\frac{\sigma^{\prime}}{\sigma_{\mathrm{r}}}\right)^{1-j}
$$

where $m$ is the modulus number and was 210 in the present study, according to Fellenius (2020); $\sigma^{\prime}$ is the mean effective stress of the soil; $j$ is the stress exponent and was 0.5 in this study, according to Fellenius (2020); and $\sigma_{\mathrm{r}}^{\prime}$ is the reference stress, which is a constant and was $100 \mathrm{kPa}$ in this study. In equation (24), $\sigma_{\mathrm{n}, \max }$ is the maximum of the normal pressure and can be calculated according to Zhang et al. (2005)

$$
\sigma_{\mathrm{n}, \max }=K_{\mathrm{p}}^{2} \gamma z
$$

where $\gamma$ is the unit weight of the soil and can be calculated by

$$
\gamma=\rho \boldsymbol{g}
$$

where $\rho$ is the dry density of the sand and was $1542 \mathrm{~kg} / \mathrm{m}^{3}$ in this study. In equation (29), $K_{\mathrm{p}}$ is the passive earth pressure coefficient and can be calculated by

$$
K_{\mathrm{p}}=\tan ^{2}\left(45^{\circ}+\frac{\phi}{2}\right)
$$

where $\phi$ is the friction angle of the soil and was $31^{\circ}$ in this study (Ishihara, 1993). In equation (24), $\omega_{\mathrm{n}} \mathrm{f}$ max is the displacement required to mobilise the maximum stresses of the soil and can be calculated by

$$
\omega_{\mathrm{n} \_1, \max }=\frac{2 \sigma_{\mathrm{n}, \max }}{k_{\mathrm{n}, \mathrm{ini}}}
$$

When the pile moved by $\mathrm{d} a, \omega_{\mathrm{n}_{\mathrm{f}}}$ could be determined based on geometry. According to Chari \& Meyerhof (1983) and Prasad \& Chari (1999), the pile in this study could be considered a rigid pile. Thus, the displacement of a point on slice abcd, $\omega_{\mathrm{n}_{-} \mathrm{f}, 0}$, is shown in Fig. 11(a) and can be calculated by

$$
\omega_{\mathrm{n}_{-} \mathrm{f}, 0}=\left|\frac{D_{\mathrm{R}}-D}{D_{\mathrm{R}}+e_{\mathrm{L}}}\right| \mathrm{d} a
$$

where $e_{\mathrm{L}}$ is the eccentricity of the lateral load and was $50 \mathrm{~mm}$ in this study. $D_{\mathrm{R}}$ is the depth of the RC and can be calculated according to Prasad \& Chari (1999)

$$
\begin{aligned}
D_{\mathrm{R}}= & {\left[-\left(0.567 L_{\mathrm{p}}+2 \cdot 7 e_{\mathrm{L}}\right)+\left(5 \cdot 307 L_{\mathrm{p}}^{2}+7.29 e_{\mathrm{L}}^{2}\right.\right.} \\
& \left.\left.+10.541 e_{\mathrm{L}} L_{\mathrm{p}}\right)^{0.5}\right] / 2 \cdot 1996
\end{aligned}
$$

where $L_{\mathrm{p}}$ is the embedded length of the pile and was $100 \mathrm{~mm}$ in this study. According to equation (34), the value of $D_{\mathrm{R}}$ was $73 \mathrm{~mm}$. 


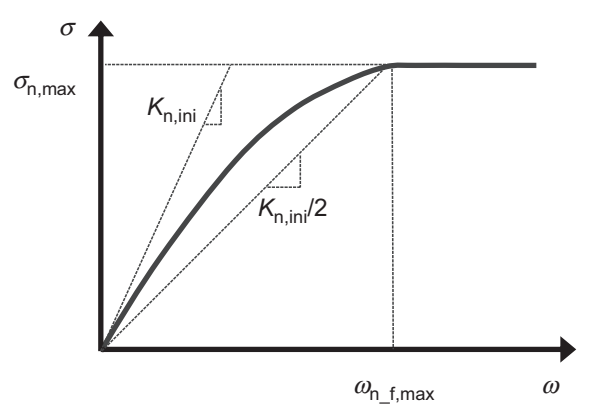

(a)

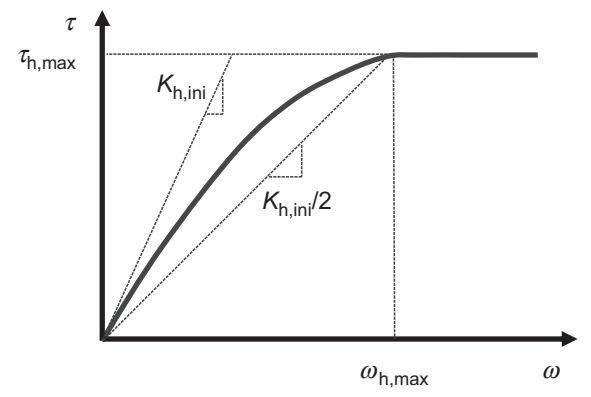

(c)

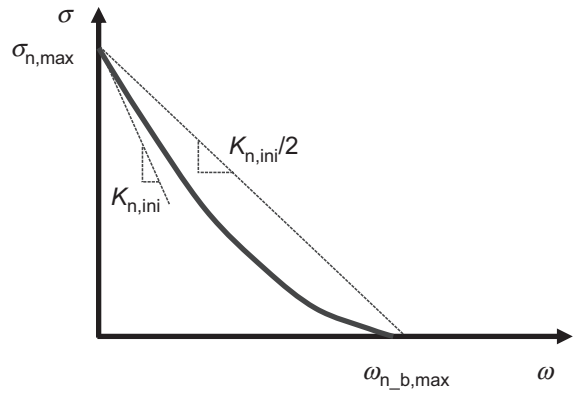

(b)

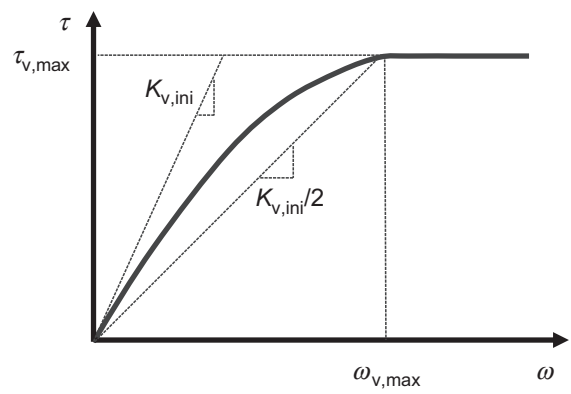

(d)

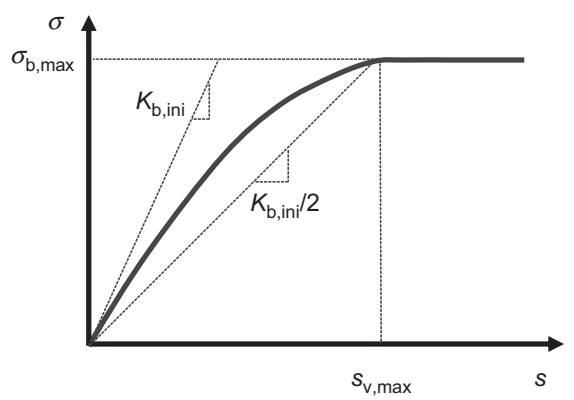

(e)

Fig. 10. Load-transfer curves: (a) $\sigma_{n_{\_} \_}-\omega_{n_{\_} \_} ;$(b) $\sigma_{n_{n} \_b}-\omega_{n_{n} b} ;$ (c) $\tau_{h}-\omega_{h} ;$ (d) $\tau_{v}-\omega_{v} ;$ (e) $\sigma_{b}-s_{v}$

The displacement of the pile on the front side, $\omega_{\mathrm{n}_{\_}}$, is shown in Fig. 11(b) and can be calculated by

$$
\omega_{\mathrm{n}_{-} \mathrm{f}}=\left|\omega_{\mathrm{n}_{-} \mathrm{f}, 0} \cos \theta\right|
$$

(b) On the back side of the pile, the relationship curve between the normal pressure, $\sigma_{\mathrm{n}_{\mathrm{b}} \mathrm{b}}$, and the normal displacement of the soil, $\omega_{\mathrm{n} \_\mathrm{b}}$, is shown in Fig. 10(b) and can be expressed by

$$
\sigma_{\mathrm{n} \_\mathrm{b}}=\left\{\begin{array}{cl}
\frac{k_{\mathrm{n}, \text { ini }}}{2} \frac{\left(\omega_{\mathrm{n} \_\mathrm{b}}-\omega_{\mathrm{n} \_\mathrm{b}, \max }\right)^{2}}{\omega_{\mathrm{n} \_\mathrm{b}, \max }}, & \text { if } \omega_{\mathrm{n}}<\omega_{\mathrm{n} \_ \text {b } \max } \\
0, & \text { otherwise }
\end{array}\right.
$$

where $\omega_{\mathrm{n} \_ \text {b,max }}$ is the displacement when the stress is reduced to 0 and can be expressed by

$$
\omega_{\mathrm{n} \_ \text {b } \max }=\frac{2 \sigma_{\mathrm{n}, \max }}{k_{\mathrm{n}, \text { ini }}}
$$

$\omega_{\mathrm{n} \_\mathrm{b}}$ is shown in Fig. 11(b) and can be calculated by

$$
\omega_{\mathrm{n} \_\mathrm{b}}=\left|\omega_{\mathrm{n}_{\_} \mathrm{f}, 0} \cos \theta\right|
$$

\section{Load-transfer curve for $\tau_{h}$}

The relationship curve between the horizontal shear stress, $\tau_{\mathrm{h}}$, and the normalised shearing displacement of the soil, $\omega_{\mathrm{h}} / r$, is shown in Fig. 10(c) and can be expressed by

$$
\tau_{\mathrm{h}}=\left\{\begin{array}{cl}
\tau_{\mathrm{h}, \text { max }}-\frac{k_{\mathrm{h}, \text { ini }}}{2} \frac{\left(\omega_{\mathrm{h}}-\omega_{\mathrm{h}, \text { max }}\right)^{2}}{\omega_{\mathrm{h}, \text { max }} r}, & \text { if } \omega_{\mathrm{h}}<\omega_{\mathrm{h}, \text { max }} \\
\tau_{\mathrm{h}, \text { max }}, & \text { otherwise }
\end{array}\right.
$$

where $r$ is the radius of the pile, and $k_{\mathrm{h}, \text { ini }}$ is the initial gradient of the curves, which can be calculated by Li et al. (2012)

$$
k_{\mathrm{h}, \text { ini }}=\frac{G_{\mathrm{s}, \text { ini }}}{\varsigma}
$$

where $\zeta$ is the dimensionless coefficient and is equal to 4 (Li et al., 2012) in equation (24) (equation (39)), and $\tau_{\mathrm{h}, \max }$ is the maximum horizontal shear stress and can be calculated by

$$
\tau_{\mathrm{h}, \max }=\sigma_{\mathrm{n}} \tan \delta
$$

where $\sigma_{\mathrm{n}}$ is the normal pressure, $\sigma_{\mathrm{n}}$ is equal to $\sigma_{\mathrm{n}_{-} \mathrm{f}}$ on the front side of the pile, $\sigma_{\mathrm{n}}$ is equal to $\sigma_{\mathrm{n} b}$ on the back side of the pile, and $\delta$ is the interface friction angle between the pile and soil and was $0.8 \phi$ in the present study, following Zhang et al. (2005). In equation (24) (equation (39)), $\omega_{\mathrm{h}, \max }$ is the shearing displacement required to mobilise the maximum horizontal shearing stress and can be calculated by

$$
\omega_{\mathrm{h}, \max }=\frac{2 r \tau_{\mathrm{h}, \max }}{k_{\mathrm{h}, \mathrm{ini}}}
$$

$\omega_{\mathrm{h}}$ is shown in Fig. 11(b) and can be calculated by

$$
\omega_{\mathrm{h}}=\left|\omega_{\mathrm{n}_{-} \mathrm{f}, 0} \sin \theta\right|
$$

\section{Load-transfer curve for $\tau_{v}$}

The relationship curve between the vertical shear stress, $\tau_{v}$, and the normalised shearing displacement of the soil, $\omega_{\mathrm{v}} / r$, is shown in 


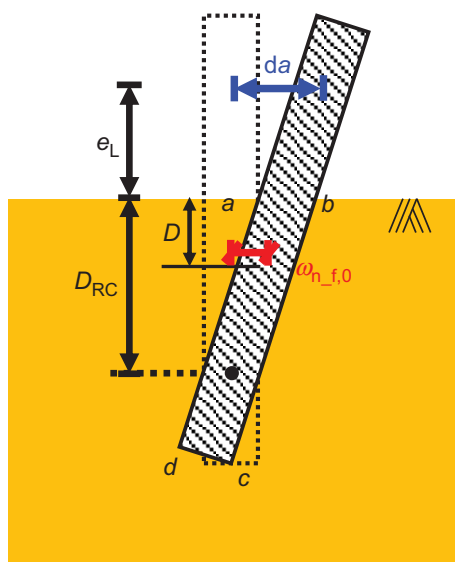

(a)

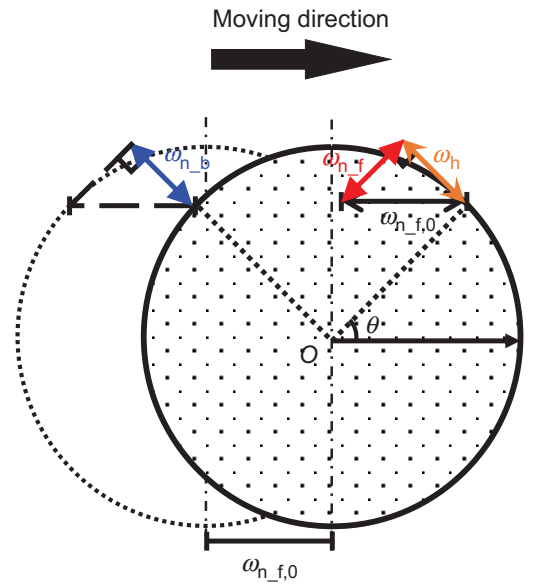

(b)

Fig. 11. Derivation of $\omega_{n_{-} f}, \omega_{n_{\_} b}$ and $\omega_{h}$ based on da: (a) relationship

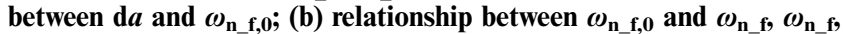
$\omega_{\mathbf{h}}$

Fig. 10(d) and can be expressed by

$$
\tau_{\mathrm{v}}=\left\{\begin{array}{cl}
\tau_{\mathrm{v}, \max }-\frac{k_{\mathrm{v}, \text { ini }}}{2} \frac{\left(\omega_{v}-\omega_{\mathrm{v}, \text { max }}\right)^{2}}{\omega_{\mathrm{h}, \text { max }} r}, & \text { if } \omega_{\mathrm{v}}<\omega_{\mathrm{v}, \max } \\
\tau_{\mathrm{v}, \text { max }}, & \text { otherwise }
\end{array}\right.
$$

where $k_{\mathrm{v}, \text { ini }}$ is the initial gradient of the curves and can be calculated by

$$
k_{\mathrm{v}, \text { ini }}=\frac{G_{\mathrm{s}, \text { ini }}}{\varsigma}
$$

In equation (24) (equation (44)), $\tau_{\mathrm{v}, \max }$ is the maximum vertical shear stress and can be obtained by

$$
\tau_{\mathrm{v}, \max }=\sigma_{\mathrm{n}} \tan \delta
$$

$\omega_{\mathrm{v}, \max }$ is the vertical shear displacement required to mobilise the maximum vertical shear stresses and can be calculated by

$$
\omega_{\mathrm{v}, \max }=\frac{2 r \tau_{\mathrm{v}, \max }}{k_{\mathrm{v}, \text { ini }}}
$$

Because the pile in this study was considered a rigid pile, $\tau_{\mathrm{v}}$ was equal to the settlement of the pile for each movement of $\mathrm{d} a$.

\section{Load-transfer curve for $\sigma_{b}$}

The relationship curve between the base pressure, $\sigma_{\mathrm{b}}$, and the settlement of the pile, $s_{\mathrm{v}}$, is shown in Fig. 10(e) and can be expressed by

$$
\sigma_{\mathrm{b}}=\left\{\begin{array}{cl}
\sigma_{\mathrm{b}, \text { max }}-\frac{k_{\mathrm{b}, \text { ini }}}{2} \frac{\left(s_{\mathrm{v}}-s_{\mathrm{v}, \text { max }}\right)^{2}}{s_{\mathrm{v}, \max }}, & \text { if } s_{\mathrm{v}}<s_{\mathrm{v}, \max } \\
\sigma_{\mathrm{b}, \max }, & \text { otherwise }
\end{array}\right.
$$

where $k_{\mathrm{b}, \text { ini }}$ is the initial gradient of the curves and can be expressed according to Li et al. (2012)

$$
k_{\mathrm{b}, \mathrm{ini}}=\frac{8}{\pi(1-v) D} G_{\mathrm{s}, \mathrm{ini}}
$$

In equation (24) (equation (48)), $s_{\mathrm{v}, \max }$ is the displacement required to mobilise the maximum stress of the base pressure and can be calculated by Li et al. (2012)

$$
s_{\mathrm{v}, \max }=\lambda D
$$

where $\lambda$ is the coefficient that reflects the effect of the pile installation methods on the capacities of the base soil and was $0 \cdot 2$ in this study, according to $\mathrm{Li}$ et al. (2012). In equation (24) (equation (48)), $\sigma_{\mathrm{b}, \max }$ is the maximum base pressure and can be calculated by

$$
\sigma_{\mathrm{b}, \max }=\frac{k_{\mathrm{b}, \mathrm{ini}} s_{\mathrm{V}, \max }}{2}
$$

In this study, all calculations of the pile settlement were implemented using Matlab with self-coded programs.

\section{APPENDIX 2. STEPS FOR \\ SETTLEMENT-CONTROLLED DESIGN}

The 'settlement-controlled design' steps are shown in Fig. 12. In a traditional pile design, the designers are mainly concerned as to whether the pile capacities (vertical capacity and horizontal capacity) are sufficient - that is, larger than the external loads (vertical load, $F_{\mathrm{v}}$, and horizontal load, $F_{\mathrm{h}}$ ). However, this study found that the settlement of the pile under cyclic lateral loading should also be considered. In the settlement-controlled pile design, judgements can be made first according to the design plane shown in Fig. 9. This helps avoid non-convergent settlements of the pile under cyclic lateral loads. Then, the settlements of the pile can be

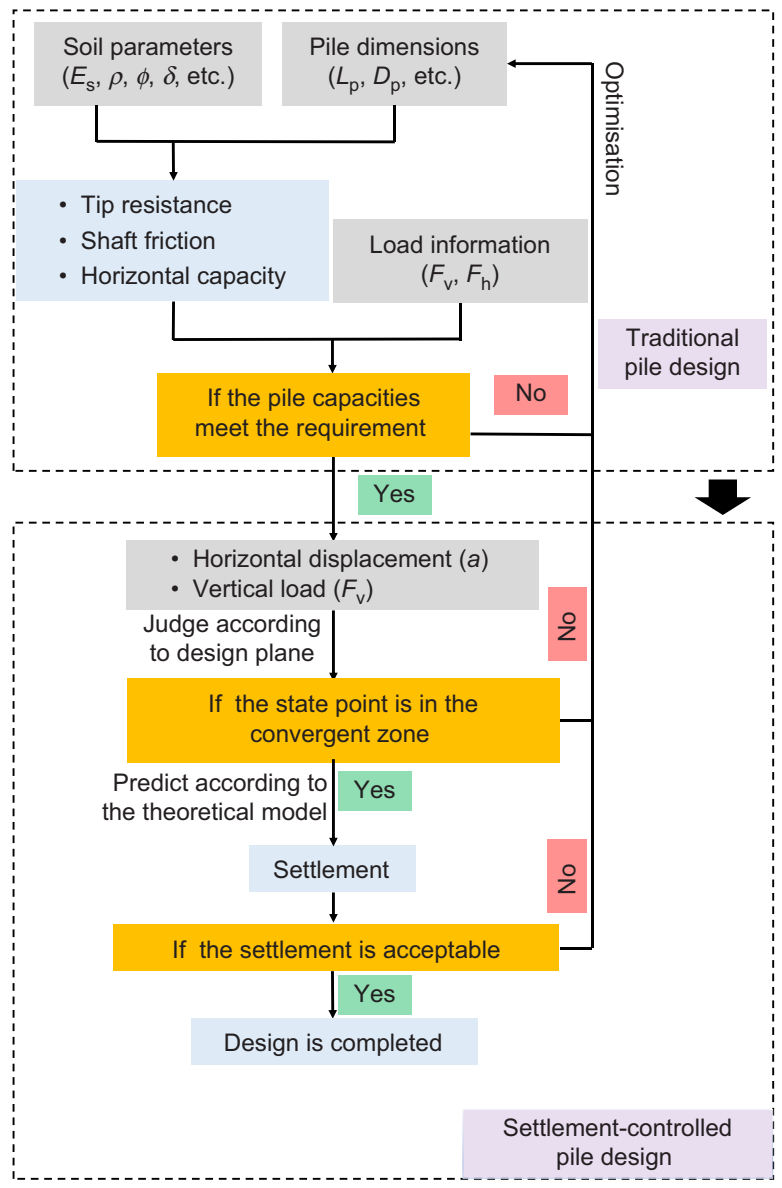

Fig. 12. Flow chart of the settlement-controlled pile design 
calculated according to the proposed theoretical model. If the value of the predicted settlements is acceptable, the design is completed; otherwise, the design should be further optimised (e.g. soil parameters and pile dimensions can be changed).

\section{NOTATION}

a amplitude of horizontal displacement of cyclic lateral loads

$a_{i}$ horizontal displacement of pile at the $i$ th half-cycle movement

$D_{\mathrm{p}}$ diameter of pile

$D_{\mathrm{RC}}$ depth of rotation centre (RC)

$\mathrm{d} F_{\mathrm{f}_{-} \mathrm{d} a}$ loss in mobilised shaft friction in a $\mathrm{d} a$ movement

$\mathrm{d} F_{\mathrm{f}_{-} \mathrm{d} a, \mathrm{~b}}$ forces transmitted to pile base in a $\mathrm{d} a$ movement

$\mathrm{d} s_{\mathrm{v}}$ pile settlement in a $\mathrm{d} a$ movement

$E_{\mathrm{s}} \quad$ Young's modulus of the soil

$e_{\mathrm{L}} \quad$ eccentricity of the lateral load

$F_{\mathrm{h}}$ horizontal load

$F_{\mathrm{M} 0}$ mobilised shaft friction of pile before cyclic lateral loading

$F_{\mathrm{v}} \quad$ vertical load

$f_{\mathrm{b}}$ force acting on pile base

$f_{\mathrm{b} 0}$ initial tip resistance

$f_{\mathrm{b}, \max }$ maximum tip resistance

$G_{0}$ shear modulus of the soil

$G_{\mathrm{s}, \text { ini }}$ initial shear modulus of the soil

$g$ acceleration of gravity

$i$ number of half-cycle movements

$j$ stress exponent

$K_{\mathrm{b} \_\mathrm{d} a} \quad$ contribution of pile base to stiffness of pile against vertical displacement

$K_{\mathrm{p}} \quad$ passive earth pressure coefficient

$K_{\mathrm{s} \_\mathrm{d} a} \quad$ contribution of pile shaft to stiffness of pile against vertical displacement

$k_{\mathrm{b}, \text { ini }} \quad$ initial gradient of the load-transfer curve for $\sigma_{\mathrm{b}}$

$k_{\mathrm{h} \text {,ini }}$ initial gradient of the load-transfer curve for $\tau_{\mathrm{h}}$

$k_{\mathrm{h} \_\mathrm{QP}} \quad$ slope of the load-transfer curves corresponding to $\tau_{\mathrm{h}}$ in quick prediction formula

$k_{\mathrm{n}, \mathrm{ini}}$ initial gradient of the load-transfer curve for $\sigma_{\mathrm{n} \_}$

$k_{\mathrm{n} \_\mathrm{QP}} \quad$ slope of the load-transfer curves corresponding to $\sigma_{\mathrm{n}}$ in quick prediction formula

$k_{\mathrm{v}, \text { ini }}$ initial gradient of the load-transfer curve for $\tau_{\mathrm{v}}$

$k_{\mathrm{v}-\mathrm{QP}}$ slope of the load-transfer curves corresponding to $\tau_{\mathrm{v}}$ in quick prediction formula

$L_{\mathrm{p}} \quad$ embedded length of the pile

$m$ modulus number

$n$ cycle number of cyclic lateral loads

$r$ radius of the pile

$S$ surface of the pile shaft

$S_{j_{-} \mathrm{QP}} \quad$ settlement of a pile under cyclic lateral loads for quick prediction after $j$ half-cycle movements

$S_{\mathrm{v}} \quad$ pile settlement

$s_{\mathrm{V}, \max }$ displacement required to mobilise the maximum stress of the base pressure $\left(\sigma_{\mathrm{b}, \max }\right)$

$\alpha$ sign function

$\beta$ dimensionless coefficient

$\gamma \quad$ unit weight of the soil

$\Delta F_{\mathrm{M} \_\mathrm{QP}} \quad$ loss of shaft friction of pile during the lateral loading process in quick prediction formula

$\delta \quad$ friction angle of pile-soil interface

$\zeta$ dimensionless coefficient

$\eta_{\mathrm{QP}}$ ratio

$\lambda$ coefficient that reflects the effect of the pile installation methods on the capacities of the base soil

$v$ Poisson's ratio of the sand

$\rho$ dry density of the sand

$\sigma^{\prime} \quad$ mean effective stress of the soil

$\sigma_{\mathrm{r}}^{\prime} \quad$ reference stress

$\sigma_{\mathrm{b}}$ base pressure

$\sigma_{\mathrm{b}, \max }$ maximum base pressure of the pile

$\sigma_{\mathrm{n}}$ normal pressure acting on the pile shaft

$\sigma_{\mathrm{n} \_\mathrm{b}} \quad$ normal pressure acting on the back side of the pile shaft

$\sigma_{\mathrm{n} \_\mathrm{d} a}$ normal pressure after pile head moves horizontally at a distance of $\mathrm{d} a$ $\sigma_{\mathrm{n}_{\mathrm{f}} \mathrm{f}}$ normal pressure acting on the front side of the pile shaft $\sigma_{\mathrm{n}, \max }$ maximum of the normal pressure

$\tau_{\mathrm{h}}$ horizontal shear stress acting on pile shaft

$\tau_{\mathrm{h}, \max }$ maximum horizontal shear stress

$\tau_{\mathrm{v}} \quad$ vertical shear stress acting on pile shaft (i.e. mobilised shaft friction)

$\tau_{\mathrm{v}, D_{1} \_0} \quad$ vertical shear stress acting on slice abcd at depth $D_{1}$ in quick prediction formula

$\tau_{\mathrm{v}, D_{1} \_\theta} \quad$ vertical shear stress acting on the pile at depth $D_{1}$ in quick prediction formula

$\tau_{\mathrm{v}, D_{1} \_ \text {ini }} \quad$ initial shear stress acting on the pile at depth $D_{1}$ in quick prediction formula

$\tau_{\mathrm{v}, D_{\mathrm{RC}}} \quad$ shaft friction at depth $D_{\mathrm{RC}}$ in quick prediction formula

$\tau_{\mathrm{v}, \max }$ maximum vertical shear stress

$\phi$ friction angle of the soil

$\chi$ coefficient that reflects the effect of the pile installation procedure on the shear modulus of the soil

$\omega_{\mathrm{h}}$ horizontal shearing displacement of the soil

$\omega_{\mathrm{h}, \max }$ shearing displacement required to mobilise the maximum horizontal shearing stress $\left(\tau_{\mathrm{h}, \max }\right)$

$\omega_{\mathrm{n} \_\mathrm{b}} \quad$ normal displacement of the soil on the back side

$\omega_{\mathrm{n} \_ \text {b }, \text { max }}$ displacement when the normal stress $\left(\sigma_{\mathrm{n} \_\mathrm{b}}\right)$ is reduced to 0

$\omega_{\mathrm{n} \_\mathrm{f}}$ normal displacement of the soil on the front side

$\omega_{\mathrm{n} \_\mathrm{f}, \max }$ displacement required to mobilise the maximum stresses $\left(\sigma_{n, \max }\right)$ of the soil

$\omega_{\mathrm{v}}$ vertical shearing displacement of the soil

$\omega_{\mathrm{v}, \max }$ vertical shear displacement required to mobilise the maximum vertical shear stresses $\left(\tau_{\mathrm{v}, \max }\right)$

\section{REFERENCES}

AHG (Alexander Howden Group Limited) (1995). The Great Hanshin earthquake, Japan - a report of the 1995 earthquake in Kobe and the Osaka Bay area and assessment of future insurance implications. London, UK: AHG.

API (American Petroleum Institute) (2015). 19901-4:2003: Geotechnical and foundation design considerations. Washington, DC, USA: API.

Baguelin, F., Frank, R. \& Said, Y. H. (1977). Theoretical study of lateral reaction mechanism of piles. Géotechnique 27, No. 3, 405-434, https://doi.org/10.1680/geot.1977.27.3.405

Banerjee, P. K. \& Davies, T. G. (1978). The behaviour of axially and laterally loaded single piles embedded in non-homogeneous soils. Géotechnique 28, No. 3, 309-326, https://doi.org/10.1680/ geot.1978.28.3.309.

Broms, B. B. (1964). Lateral resistance of piles in cohesionless soils. ASCE J. Soil Mech. Found. Div. 90, No. SM3, 123-156.

BSI (1997). BS EN 1997: Eurocode 7: Geotechnical design. London, UK: BSI.

Budhu, M. \& Davies, T. G. (1987). Nonlinear analysis of laterally loaded piles in cohesionless soil. Can. Geotech. J. 24, No. 2, 289-296.

Chari, T. R. \& Meyerhof, G. G. (1983). Ultimate capacity of rigid single piles under inclined loads in sand. Can. Geotech. J. 20 No. 4, 849-854.

EQE (1995). The January 17, 1995 Kobe earthquake (an EQE summary report). San Francisco, CA, USA: EQE International.

Fellenius, B. H. (2020). Basics of foundation design. Sidney, BC, Canada: B. Fellenius. See https://www.Fellenius.net (accessed 07/01/2022).

Hamada, M. \& O'Rourke, T. D. (1992). Case studies of liquefaction and lifeline performance during past earthquakes, volume 1, Japanese case studies, NCEER-92-0001. Buffalo, NY, USA: NCEER (National Center for Earthquake Engineering Research).

Hong, Y., He, B., Wang, L. Z., Wang, Z., Ng, C. W. W. \& Mašín, D. (2017). Cyclic lateral response and failure mechanisms of a semi-rigid pile in soft clay: centrifuge tests and numerical modelling. Can. Geotech. J. 54, No. 6, 806-824.

Ishihara, K. (1993). Liquefaction and flow failure during earthquakes. Géotechnique 43, No. 3, 351-415, https://doi. org/10.1680/geot.1993.43.3.351.

Janbu, N. (1998). Sediment deformation. Bulletin 35. Trondheim, Norway: University of Trondheim, Norwegian University of Science and Technology. 
Kong, D. Q., Wen, K., Zhu, B., Zhu, Z. \& Chen, Y. (2019). Centrifuge modeling of cyclic lateral behaviors of a tetrapod piled jacket foundation for offshore wind turbines in sand. J. Geotech. Geoenviron. Engng 145, No. 11, 04019099, https://doi.org/10.1061/(ASCE)GT.1943-5606.0002160.

Leblanc, C., Houlsby, G. T. \& Byrne, B. W. (2010). Response of stiff piles in sand to long-term cyclic lateral loading. Géotechnique 60, No. 2, 79-90, https://doi.org/10.1680/geot.7.00196.

Li, M. Z., Bolton, M. D. \& Haigh, S. K. (2012). Cyclic axial behavior of piles and pile groups in sand. Can. Geotech. J. 49, No. 9, 1074-1087.

Liu, C., Sun, Y. N., Zheng, G., Liu, Y. C., Hu, Q. B. \& Yp, L. (2018). Experimental study on the seismic performance of the prestressed high-strength concrete pipe pile reinforced with nonprestressed steel bars. Chin. Civ. Engng J. 51, No. 4, 77-86 (in Chinese).

Matlock, H. (1970). Correlations for design of laterally loaded piles in soft clay. Proceedings of the 2nd offshore technology conference, Houston, TX, USA, vol. 1, OTC 1204, pp. 577-594.

Mendoza, M. J. \& Auvinet, G. (1988). The Mexico earthquake of September 19, 1985 - behavior of building foundations in Mexico City. Earthq. Spectra 4, No. 4, 835-853.

Meyerhof, G. G. (1995). Behavior of pile foundations under special loading conditions; 1994 R.M. Hardy keynote address. Can. Geotech. J. 32, No. 2, 204-222.

Meyerhof, G. G., Mathur, S. K. \& Valsangkar, A. J. (1981). Lateral resistance and deflection of rigid wall and piles in layered soils. Can. Geotech. J. 18, No. 2, 159-170.

MOHURD (Ministry of Housing and Urban-Rural Development of the People's Republic of China) (2008). JGJ 94-2008: Technical code for building pile foundations. Beijing, China: MOHURD.

Ng, C. W. W., Springman, S. M. \& Norrish, A. R. M. (1998a). Centrifuge modeling of spread-base integral bridge abutments. J. Geotech. Geoenviron. Engng 124, No. 5, 376-388.

Ng, C. W. W., Springman, S. M. \& Norrish, A. R. M. (1998b). Soilstructure interaction of spread-base integral bridge abutments. Soils Found. 38, No. 1, 145-162.

Poulos, H. G., Chen, L. T. \& Hull, T. S. (1995). Model test on single piles subjected to lateral soil movement. Soils Found. 35, No. 4, 85-92.

Prasad, Y. V. S. N. \& Chari, T. R. (1999). Lateral capacity of model rigid piles in cohesionless soils. Soils Found. 39, No. 2, $21-29$.
Randolph, M. F. (1981). The response of flexible piles to lateral loading. Géotechnique 31, No. 2, 247-259, https://doi.org/ 10.1680/geot.1981.31.2.247.

Randolph, M. F. (2003). Science and empiricism in pile foundation design. Géotechnique 53, No. 10, 847-875, https://doi. org/10.1680/geot.2003.53.10.847.

Randolph, M. \& Schneider, J. (2018). Pile foundations: design for axial and lateral loading. In Encyclopedia of maritime and offshore engineering, Vol. 6 Ocean renewable energy (eds J. Carlton, P. Jukes and Y. S. Choo), Ch. 289, pp. 3811-3834. Chichester, UK: John Wiley \& Sons.

Reese, L. C., Cox, W. R. \& Koop, F. D. (1974). Analysis of laterally loaded piles in sand. Proceedings of the offshore technology conference, Houston, TX, USA, OTC 2080, pp. 473-483.

Rollins, K. M., Peterson, K. J. \& Weaver, T. J. (1998). Lateral load behavior of full-scale pile group in clay. J. Geotech. Geoenviron. Engng 124, No. 6, 468-478.

Sun, K. \& Pires, J. A. (1993). Simplified approach for pile and foundation interaction analysis. J. Geotech. Engng 119, No. 9, $1462-1479$.

Stringer, M. E. \& Madabhushi, S. P. G. (2011). Axial load transfer in liquefiable soils for free-standing piles. Géotechnique 63, No. 5, 400-409, https://doi.org/10.1680/geot.11.P.078.

Tokimatsu, K. \& Asaka, Y. (1998). Effects of liquefaction-induced ground displacements on pile performance in the 1995 Hyogoken-Nambu earthquake. Soils Found. 38, Special Issue No. 2, 163-177.

Zhang, L. Y. (2009). Nonlinear analysis of laterally loaded rigid piles in cohesionless soils. Comput. Geotech. 36, No. 5, 718-724.

Zhang, L. Y., Silva, F. \& Grismala, R. (2005). Ultimate lateral resistance to piles in cohesionless soils. J. Geotech. Geoenviron. Engng 131, No. 1, 78-83.

Zhang, C. R., White, D. \& Mark, R. (2011). Centrifuge modelling of the cyclic lateral response of a rigid pile in soft clay. J. Geotech. Geoenviron. Engng 137, No. 7, 717-729.

Zhang, C. R., Yu, J. \& Huang, M. S. (2016). Winkler load-transfer analysis for laterally loaded piles. Can. Geotech. J. 53, No. 7, $1110-1124$

Zheng, G., Sun, J. B., Zhang, T. Q., Jiao, Y. \& Diao, Y. (2021). Centrifuge model testing to ascertain vertical displacements of a pile under cyclic lateral loads. J. Zhejiang Univ. Sci. A 22, No. 9, $760-766$. 